\title{
Analysis of DVB-T2 and LTE Networks Co-Existence in the Digital Dividend Band in Nigeria
}

\author{
Evans C. Ashigwuike, Sadiq A. Umar, and Stephen O. Okpanachi Moses
}

\begin{abstract}
This paper, present results of the analysis of DVBT2 and LTE network co-existence in Nigeria. The Spectrum Engineering Advanced Monte Carlo Analysis Tool (SEAMCAT) used to analyse the co-existence. The findings of the study reveals that the blocking interference is the dominant effect and to ensure that the probability of interference is below the threshold of $5 \%$. It is mandatory to decrease the transmission power of the LTE from $196 \mathrm{mw}$ to $25 \mathrm{mw}$. Consequently, the protection ratio for DVB-T2 and LTE should be maintained for a seamless co-existence.
\end{abstract}

Index Terms-Co-existence, DVB-T2, Interference at 700MHz and LTE.

\section{INTRODUCTION}

A good number of countries in the world are migrating terrestrial analogue television systems to digital technology [1]. With this transformation, fractions of spectrum occupied by television will be offered for use by wireless broadband communication systems [1]. This judgment from the economic point of view is very good, but the implementation might raise new challenges in co-existence that need to be carefully analyzed and evaluated [1]. Results of such studies can help to assure that, within a shared frequency band; new systems can operate without performance degradation while existing services are protected and as well propose practical guidelines for efficient spectrum usage and reliable services in Nigeria [1].

Previous studies on ways of preventing expected harmful interference impacts between new and former systems, [2-5] failed to explore the Nigerian case. The major challenge facing the ITU is that spectrum sharing studies are difficult to standardize globally, as each country has its own spectrum planning scheme [6]. Thus, each country must conduct its own spectrum sharing studies. Both co-channel and adjacent channel interference may occur between the two services. If, for example, Nigeria completes the Analogue Switch Over (ASO) phase and deploys mobile services in the $694-862 \mathrm{MHz}$ sub-band, while neighboring country like the Republic of Benin is in a transition period of switching from analogue to DVB-T2 and still using the 694-862 MHz sub-band for broadcasting services, then cochannel interference will occur in radio communication

Published on June 15, 2020

E. C. Ashigwuike, Department of Electrical and Electronics Engineering, Univerisity of Abuja, F.C.T, Nigeria.

(e-mail: ecashigwuike@ymail.com).

S. A. Umar, National Space Research and Development Agency (NASRDA), Nigeria.

(e-mail: sadiqumar2001@googlemail.com).

S. O. Okpanachi Moses, Nigerian Television Authority, F.C.T, Nigeria.

(e-mail: Stephen.moses@nta.gov.ng). between the Nigeria and Benin. Likewise, adjacent channel interference may occur in Nigeria between two services operating within the same geographical region. For instance, Nigeria deploys mobile service in the 694-862 MHz subband where DVB-T2 service is already operational in the 470-694 MHz band; the two systems will experience adjacent channels interference with each other even though they are separated in the frequency domain. Such interference will be more challenging when both services are active and cover the same area (i.e., a co-cited situation).

Nigeria's digital dividend is within the frequency range of $694 \mathrm{MHz}$ to $862 \mathrm{MHz}$ that is from channel 48 to channel 69. When LTE FDD services are deployed in the digital dividend, channel 48 will be the most affected television channel. Channel 48 lies within the frequency range of $687 \mathrm{MHz}$ to $694 \mathrm{MHz}$.

\section{RELATED WORK}

The prior work done, studied the theoretical analysis of co-channel interference between DVB-T2 and LTE has been presented in [1-5]. Co-existence in terms of DVB-T access coverage loss and outage probability has been considered in [7] and [8]. In [3] and [9], simulation analyses were carried out to compute approximately the adjacent channel interfering effects of LTE Base Station and User Equipment (UE) on DVB-T receiver systems. The author of [10], presented the simulation of the adjacent channel interference effects of the LTE FDD DL on DVB-T home receivers (only for channel 60) have been simulated. The coexistence between digital terrestrial television and LTE network in the new spectrum allocated from mobile communications 700 $\mathrm{MHz}$ bands have been investigated in [1].

\section{MATERIALS AND METHOD}

The Monte Carlo Simulation method employed to access the total interfering signal which is regarded as the sum of the unwanted emissions and blocking signal present in the television receiver as a resultant effect of the transmissions made from the base stations into the user equipment. The simulations under the Monte Carlo method are carried out with Spectrum Engineering Advanced Monte Carlo Analysis Tool (SEAMCAT) software developed by CEPT (European Conference of Postal and Telecommunications Administrations) [11]. The propagation loss of the television signal was determined by employing the model in recommendation ITU-R P.1546 [12] while for the LTE eNodeB, the researcher employed Extended Hata for propagation loss model [13] and User Equipment used Extended Hata SRD [14] for propagation loss model. 
The implementation of mobile services in the $694-790$ $\mathrm{MHz}$ band can cause signal interference on the television receivers in home environments. The radio interference between various services is generally mitigated by employing guard bands or by ensuring satisfactory geographical separation. For mobile LTE networks, deployed in the UHF band, the guard band was set to $9 \mathrm{MHz}$ from the edge of Channel 48 for television broadcasting as illustrated in Fig. 1.

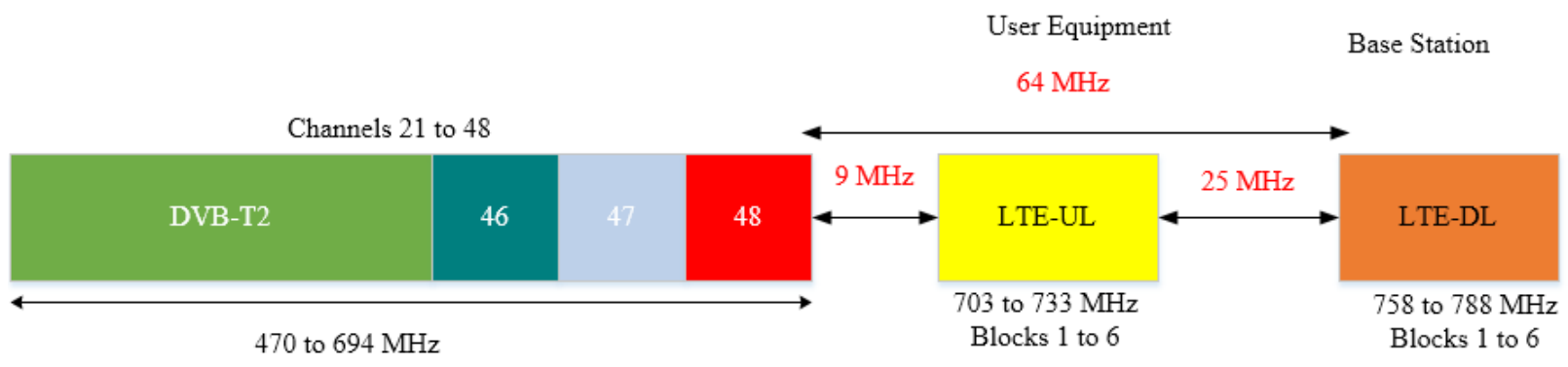

Fig. 1. Spectrum Plan for the $700 \mathrm{MHz}$ band [8]

The close proximity of the transmission frequencies of the LTE base stations and DVB-T2 transmitters can lead to digital television service interference in some locations, but mainly on the coverage borders. Transmitter power, base station location, mobile services network infrastructure, antennas, and network topologies are totally different for digital terrestrial television transmission DVB-T2 and for cellular mobile networks. Because of these differences, one can expect that the number of interferences will raise. Antennas used for reception of television broadcasting installed before the year 2013 were designed to receive VHF Band III and UHF Bands IV and V up to $862 \mathrm{MHz}$, which exceeds Channel 48. Since LTE is deployed in the band from $694 \mathrm{MHZ}$ to $790 \mathrm{MHz}$, television systems are subjected by interference, in particular, upper channels up to Channel 48. Interference scenario consider for this study is LTE influence on DVB-T2 - in this case, the LTE transmitter is the interferer to the digital television receiving equipment. The interference can be caused either by LTE terminal (user equipment) transmitting the uplink signal or LTE base station transmitting the downlink signal. In the case of terrestrial TV signals, neighbouring channel scenarios can occur. The LTE interference on the DVB-T2 results to degradation of the sensitivity, resulting to loss of signal and reduction of coverage of digital television system. These clearly justify the present challenge of free television in Abuja where free television transmission cannot be received in some areas like Abaji, Kwali, Arozo and Karishi.

\section{RESUlTS AND DISCUSSION}

The LTE system layout is illustrated in Fig. 2 which comprise of hexagonal cells with a 1,000 to $4,000 \mathrm{~m}$ diameter, conventionally utilized in metropolitan areas [5]. Each of the 19 cells was separated into three segments, as shown in Fig. 2.

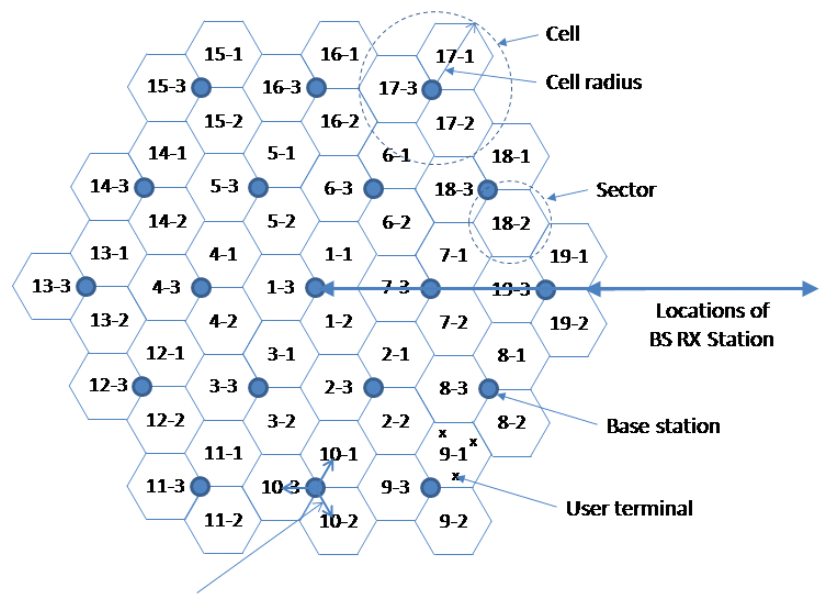

Base station antenna pointing directions

Fig. 2. Three segment macrocells scenarios

Each segment has maximum of 21 users (User Equipment) that are arbitrarily located in each step of the simulation. The UE are located indoor environments $1 \mathrm{~m}$ aside from the Set Top Box( receivers) and $1 \mathrm{~m}$ above the floor. The intrusion of the LTE system operating with a 10 $\mathrm{MHz}$ band, with mid-band frequencies were $713 \mathrm{MHz}$ for the User Equipment's and $765 \mathrm{MHz}$ for the eNodeB's, on the DVB-T2 channel 48 was calculated. The simulations examined television coverage areas of 10 and $20 \mathrm{~km}$. The distance between the transmitter ( $\mathrm{Tx}$ ) and the adjoining eNodeB was set at $10 \mathrm{~m}$. The power of the DVB-T2 transmitter was adjusted between $1 \mathrm{Kw}(60 \mathrm{dBm})$ and $100 \mathrm{kw}(80 \mathrm{dBm})$.

Fig. 3 illustrates the simulated behaviour of the probability of interference (IP blocking) and unnecessary emissions (unwanted IP) as a function of the DVB-T2 transmitter EIRP. As the DVB-T2 transmitter EIRP enlarges, the $\mathrm{C} / \mathrm{I}$ ratio is enhanced and the probability of intrusion decreased. A DVB-T2 transmitter EIRP of $100 \mathrm{kw}$ $(80 \mathrm{dBm})$ is projected to generate an interference probability less than the preferred threshold of 5\%. From the study, it was revealed that blocking interference is the overriding effect, reflecting the restrictions of television reception filters. 


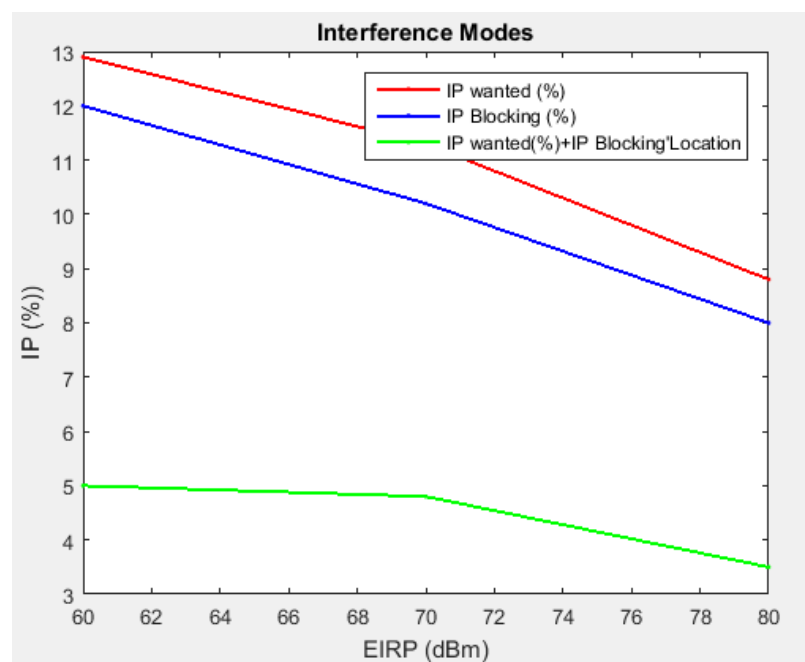

Fig. 3. Interference Probability Vs Power of TV transmitter

The mean values of interference probability, C/I (dB) ratio and percentage of television users with received signal above the reception threshold, obtained in different simulations with varying the DVB-T2 EIRP and television coverage area as illustrated in Table I. The probability of interference diminishes with the enlargement of DVB-T2 transmission power and the coverage area enlarges since users at the edge of this area will have smaller $\mathrm{C} / \mathrm{I}$ relations. The probability of interference is below 5\% only for the case in which the EIRP is equal to $100 \mathrm{kw}(80 \mathrm{dBm})$ and the television coverage area is equal to $10 \mathrm{~km}$. Note that, with DVB-T2 EIRP of $1 \mathrm{kw}(60 \mathrm{dBm})$, the percentage of users that get high-quality reception is insignificant, making this circumstance impracticable.

One can deduce that one practicable approach to minimize the interference probability is to restrict the eNodeB's and UE's emissions. In these circumstances, the number of users of the TV with the received signal level above the threshold is greater than $80 \%$ and the circumstances is considered practicable. From the foregoing, it implies that the decline of the eNodeB's power does not cause a significant enhancement in the interference probability. The basic finding here is that it is mandatory to restrict the power of the User Equipment's to 0.025watts to achieve the value for the interference probability below the threshold of $5 \%$.

TABLE I: LTE INTERFERENCE ON TV: SIMULATIONS WITH VARIABLE EIRP

\begin{tabular}{lllllll}
\multicolumn{7}{c}{ AND TV CovERAGE } \\
\hline \hline EIRP & $\begin{array}{l}\text { TV } \\
\text { coverage }(\mathrm{dBm}) \\
(\mathrm{Km})\end{array}$ & $\begin{array}{l}\text { eNodeB } \\
\text { Power } \\
(\mathrm{dBm})\end{array}$ & $\begin{array}{l}\text { UE } \\
\text { Power } \\
(\mathrm{dBm})\end{array}$ & $\begin{array}{l}\text { IP } \\
(\%)\end{array}$ & $\begin{array}{l}\text { C/I } \\
(\mathrm{dB})\end{array}$ & $\begin{array}{l}\text { Active } \\
\text { TV users } \\
(\%)\end{array}$ \\
\hline 60 & 10 & 46 & 23 & 12.8 & 27.8 & 34.7 \\
60 & 20 & 46 & 23 & 13.2 & 18.2 & 9.3 \\
70 & 10 & 46 & 23 & 9.3 & 37.9 & 83.9 \\
70 & 20 & 46 & 23 & 11.2 & 28.3 & 35.2 \\
80 & 10 & 46 & 23 & 3.8 & 47.7 & 99.5 \\
80 & 20 & 46 & 23 & 8.7 & 38.3 & 80.5 \\
\hline \hline
\end{tabular}

The fluctuations in the $\mathrm{C} / \mathrm{I}(\mathrm{dB})$, probability of interference, the mean transmission powers of the eNodeB's and the UE and $70 \mathrm{dBm}$ EIRP TV with $10 \mathrm{~km}$ coverage radius is shown in Table II.
TABLE II: LTE INTERFERENCE SIMULATIONS WITH RESTRICTION OF ENODEB AND UE TRANSMISSION POWER

\begin{tabular}{|c|c|c|c|c|c|c|}
\hline $\begin{array}{l}\text { EIRP } \\
\text { TV } \\
(\mathrm{dBm})\end{array}$ & $\begin{array}{l}\text { TV } \\
\text { Coverage } \\
(\mathrm{Km})\end{array}$ & $\begin{array}{l}\text { eNodeB } \\
\text { Power } \\
(\mathrm{dBm})\end{array}$ & $\begin{array}{l}\text { UE } \\
\text { Power } \\
(\mathrm{dBm})\end{array}$ & $\begin{array}{l}\text { IP } \\
(\%)\end{array}$ & $\begin{array}{l}\mathrm{C} / \mathrm{I} \\
(\mathrm{dB})\end{array}$ & $\begin{array}{l}\text { Active } \\
\text { TV } \\
\text { users } \\
(\%)\end{array}$ \\
\hline 70 & 10 & 46 & 23 & 9.3 & 37.9 & 83.9 \\
\hline 70 & 10 & 43 & 23 & 9.2 & 37.8 & 83.2 \\
\hline 70 & 10 & 40 & 23 & 9.0 & 37.9 & 83.3 \\
\hline 70 & 10 & 46 & 20 & 7.3 & 39.9 & 83.3 \\
\hline 70 & 10 & 46 & 17 & 5.7 & 42.5 & 83.9 \\
\hline 70 & 10 & 46 & 14 & 4.8 & 45.6 & 83.9 \\
\hline
\end{tabular}

From table II and Fig. 4, one can deduce that one practicable approach to minimize the interference probability is to restrict the eNodeB's and UE's emissions. In these circumstances, the number of users of the TV with the received signal level above the threshold is greater than $80 \%$ and the circumstances is considered practicable. From the foregoing, it implies that the decline of the eNodeB's power does not cause a significant enhancement in the interference probability.

The basic finding here is that it is mandatory to restrict the power of the User Equipment's to $14 \mathrm{dBm}$ to achieve the value for the interference probability below the threshold of $5 \%$. The results were in accord with the results found in [15], [7], [9-10].

\section{CONCLUSION}

Experience has shown that the improvement of the filters of the TV receivers is an impractible solution in practice, to this effect, two forms of interference mitigation were well thought-out, namely: limiting the transmission power of LTE user equipment (UE) and eNodeB. The eNodeB power decrease did not impact significantly the probability of interference, meaning that the interference caused by the user equipment is the dominant effect. To ensure that the probability of interference below the threshold of 5\% it then become appropriate to reduce the transmission power of the user equipment from 199.5 mwatts to 25 mwatts. Based on the researcher's findings, it is concluded that the protection ratio of DVB-T2 should be maintained for a seamless coexistence.

\section{REFERENCES}

[1] D. Okamoto, L. Mello, M. Almeida and C. Rodriguez, "Performance evalution of digital TV and LTE systems operating in the $700 \mathrm{MHz}$ band under the effect of mutual interference," Journal of Microwaves, Optoelectronics and Electromagnetic Applications, vol. 15, no. 4, pp. 441-456, 2016.

[2] A. Guidotti, D. Guiducci, C. Carciofi and M. Barbinli, "Coexistence and mutal interference between mobile and broadcasting systems," IEEE 73rd Vehicular Technology, vol. 14, no. 4, pp. 524-566, 2011.

[3] A. Tekovic, D. Bonefacic, G. Sisul and R. Nad, "Interference analysis between mobile radio and digital terrestrial television in the digital dividend spectrum," Radioengineering, vol. 26, no. 1, pp. 211-220, 2017.

[4] M. Celidonio, L. Pulcini and A. Rufini, "LTE and DVB-T coexistence : A simulation study in the UHF frequency band," Journal of Communication and Computer, vol. 9, no. 4, pp. 444-455, 2012.

[5] International Telecommunication Union (ITU), "Recommendation ITU-R BT.2337-1, Sharing and compatibility studies between digital terrestrial television broadcasting and terrestrial mobile broadband applications, including IMT, in the frequency band 
470-694/698 MHz,” ITU, Geneva, 2017.

[6] International Telecommunication Union (ITU), "Digital dividend : In sights for spectrum decisions ," ITU, Publications , Geneva, 2018.

[7] S. Basnet, "Radio frequency interference to DVB-T reception from LTE systems in adjacent bands," University of Western Sydney, Sydney, 2019.

[8] ECC, "ECC REPORT 224 : Long term vision for the UHF broadcasting band," ECC Publication, Copenhagen, 2014.

[9] J. Arnez, L. da Silva Mello, R. Carlos and P. Castellanos, "LTE femtocells interference scenario and coexistence with the Brazilian digital broadcast system," 2013 IFIP Wireless Days (WD), Valencia, 2013, pp. 1-4, doi: 10.1109/WD.2013.6686537.

[10] L.Polak, O.Kaller, M. Slanina, J. Sebesta and T. Kratochil,"Coexistence between DVB-T/T2 and LTE standards in common frequency bands" Wirelss Pers Commun Doi 10.1007/s11277-016-3191-2

[11] Electronic Communications Committee Report 252, SEAMCAT
Handbook, Copenhagen : Electronic Communications Committee, 2016

[12] International Telecommunication Union (ITU), "Recommendation ITU-R P.1546-5 : Method for point-to-area predictions for terrestrial services in the frequency range $30 \mathrm{MHz}$ to $4000 \mathrm{MHz}$," ITU, Geneva, 2019.

[13] Y. Okumura, "Field strength and its variability in VHFand UHF land -mobile radio service," Review Elect. Commun Laboratory, vol. 16, no. 9 , pp. 2 - 10, 1968

[14] M. Fuentes, C. Garcia-Pardo and C. Garro, "Coexistence of digital terrestrial television and next generation cellular networks in the $700 \mathrm{MHz}$ band," IEEE Transactions on Vehicular Technology, vol. 29 , no. 4, pp. 317 - 325, 1981. 